\title{
Defined Medical Condition Result
}

National Cancer Institute

\section{Source}

National Cancer Institute. Defined Medical Condition Result. NCI Thesaurus. Code C95332.

A medical condition that has a concise explanation of the meaning of term. 